\title{
Editorial
}

\section{The mental health status of the general public and healthcare professionals in the COVID-19 pandemic}

\author{
Sankalp Yadav ${ }^{1} *$, Gautam Rawal ${ }^{2}$ \\ ${ }^{1}$ Dept. of Medicine \& Tuberculosis, Shri Madan Lal Khurana Chest Clinic, Moti Nagar, NDMC, New Delhi, India \\ ${ }^{2}$ Dept. of Respiratory Intensive Care, Max Super Specialty Hospital, Saket, New Delhi, India
}

\section{A R T I C L E I N F O}

Article history:

Received 11-04-2020

Accepted 28-05-2020

Available online 15-06-2020
(C) 2020 Published by Innovative Publication. This is an open access article under the CC BY-NC license (https://creativecommons.org/licenses/by-nc/4.0/)
The rapid spread of the human population around the globe has resulted in a greater prevalence of many infectious diseases ${ }^{1,2}$. Human history has experienced multiple episodes of pandemics in the past with large scale morbidity and mortality ${ }^{1}$. However, these past incidences of pandemics have not paralyzed the world as the current pandemic of coronavirus disease ${ }^{1}$. The disease which was initially localized to China has now affected almost all the countries of the world ${ }^{3}$. The disease is spread by a novel strain of coronavirus called as the severe acute respiratory syndrome coronavirus 2 (SARS-CoV-2) and the resulting disease is known as coronavirus disease (COVID-19) which was formerly known as the '2019 Novel Coronavirus (2019-nCoV) Pneumonia', originated from a wet market in Wuhan, Hubei province, China in early December $2019^{3,4}$. This deadly infectious disease has affected almost all sections of society and thus no subpopulation is spared ${ }^{4}$. The biggest impact that such disease has is on the general public and the frontline workers ${ }^{4}$. These frontline workers include healthcare workers, police, sanitation staff, etc. ${ }^{5}$. Commonly these days such workers are forming the first line of society's defense against the disease caused by a coronavirus and are popularly known as 'corona warriors' 6 .

The impact of COVID-19 on the mental, physical, and overall well-being of these corona warriors and the general

\footnotetext{
* Corresponding author.

E-mail address: drsankalpyadav@gmail.com (S. Yadav).
}

public is deadly ${ }^{4}$. Health professionals, patients, and the general public are under insurmountable psychological pressure which may lead to various psychological problems, such as anxiety, fear, depression, and insomnia ${ }^{4}$. In this paper, the authors would like to highlight the impact of COVD-19 on the mental health status of the general public and the healthcare professionals.

The effect on the psychological well-being of the general population in an unprecedented pandemic is reported from several countries ${ }^{4,7}$. There are anxiety and fear of death among the general population ${ }^{4}$. The limited knowledge of this pandemic and the overwhelming news may result in anxiety and fear in the general public ${ }^{8,9}$. The reports from China and Greece have shown that there were moderateto-severe anxiety and the psychological impact on the study subjects ${ }^{4,7}$. The patients with a history of psychiatric illnesses like depression and anxiety are suffering a lot with relapses in their psychiatric issues like fear-triggered panic attacks or resurface of psychosomatic symptoms; cases with medical comorbidities, such as cardiovascular disease, have been expressing distress and associated worsening of symptoms, in particular, angina and worsening of heart failure status ${ }^{7}$. The impact on the mental health of children is also worth a mention as the schools are shut, playgrounds are closed and their movements outside the safety of their houses are restricted ${ }^{7}$. This has resulted in fear, anxiety, panic attacks, and other psychosomatic symptoms ${ }^{7}$. 
The extent of the impact of a mounting threat like COVID-19 on the healthcare professionals who form the frontline defense to quell the lethality of this coronavirus disease is very high ${ }^{7}$. These workers are directly engaged in the diagnosis, treatment, and care for patients with COVID $-19^{2}$. They are working with no or minimum breaks ${ }^{10}$. With limited resources and staff, these workers are stretched to their limits ${ }^{10}$. They are under constant emotional, physical, and mental stress ${ }^{4}$. They are devoid of the comfort of their homes with their loved ones, due to safety precautions that they have to follow, since they have to keep the social distance ${ }^{10}$. In fact, they are under deep stress due to fear of being a source to spread this infection to their families ${ }^{4}$. They have to bear the brunt of fatigue, long working hours, physical and psychological violence, and occupational burnout ${ }^{1,4}$. The hospitals are saturated with patients and there is a long queue of those who want admissions ${ }^{1}$. The inpatient departments and the intensive care units are having multiple incidences of patients not following the safety protocols ${ }^{4}$. Incidences of patients running away from the security of hospitals are also available in the literature ${ }^{11}$. In some countries, verbal and physical attacks along with discrimination with these healthcare workers are reported ${ }^{12}$. Besides, the use of personals protective equipment (PPE) for long periods results in breathing difficulties and limited access to toilet and water, resulting in subsequent physical and mental fatigue $^{4}$. In fact PPE can also result in dehydration, nausea, weight loss, etc. Also, the higher susceptibility of elder healthcare workers with or without other comorbidities like diabetes, hypertension, kidney diseases, etc. to the coronavirus has instilled a feeling of fear and resulted in depression and anxiety ${ }^{4}$. A majority of healthcare staff have reported sleep disturbances and the development of obsessive-compulsive symptoms like repeated temperature checks and sterilization ${ }^{4,12}$. Studies have reported that the severity of mental symptoms in healthcare workers was affected by age, gender, occupation, specialization, type of activities performed, and proximity to COVID-19 patients ${ }^{13}$.

In short, with the paucity of literature on the overall impacts of the COVID-19 on the healthcare professionals and general public, the only possible solution which looks feasible is the timely mental conditioning of these individuals. The healthcare staff should be given timely breaks and adequate attention should be given to their grievances. Psychological crisis intervention and related activities that are adapted in countries like China should be implemented worldwide ${ }^{4}$. The mental health-related national associations and institutes should adopt emergency psychological crisis interventions, psychological counseling, and establish psychological assistance expert groups thereby, providing professional guidance by coordinating with the health authorities ${ }^{4}$. Counseling through digital platforms could help the general population. The coronavirus disease is going to last for some time, till the development of a vaccine or a drug and thus the efforts should be aimed at the overall well-being of all individuals including the health professionals. As these are the warriors who are the only answer to the present pandemic of coronavirus. Besides, large scale studies aimed at determining the mental health status of the general public and healthcare professionals are imperative and are the need of the hour.

\section{Acknowledgments}

None.

\section{Source of Funding}

None.

\section{Conflicts of Interest}

None.

\section{References}

1. Long-term Impact of COVID-19 Pandemic on Healthcare Scenario in India. Available from URL:- https://www.expresspharma.in/amp/gue st-blogs/long-term-impact-of-covid-19-pandemic-on-healthcare-scen ario-in-india/. Last accessed 2020 on May 27.

2. Cutler D. How Will COVID-19 Affect the Health Care Economy?. Available from URL:- https://jamanetwork.com/channels/health-foru $\mathrm{m} /$ fullarticle/2764547. Last accessed 2020 on May 27.

3. Yadav S, Rawal G. Corona virus pandemic- A threat to humanity. IP Indian J Immunol Respir Med. 2020;5(1):1-3.

4. Li W, Yang Y, Liu ZH, Zhao YJ, Zhang Q, Zhang L. Progression of Mental Health Services during the COVID-19 Outbreak in China. Int J Biol Sci. 2020;16(10):1732-38.

5. Heros of the frontlines. Available from URL:- https://time.com/collec tion/coronavirus-heroes/. Last accessed 2020 on May 27.

6. COVID warriors. Available from URL:- https://covidwarriors.gov.in/. Last accessed 2020 on May 27.

7. Tsamakis K, Rizos E, Manolis A, Chaidou S, Kympouropoulos S, Spartalis E, et al. COVID-19 pandemic and its impact on mental health of healthcare professionals. Exp Ther Med. 2020;19:3451-3.

8. Shigemura J, Ursano RJ, Morganstein JC, Kurosawa M, Benedek DM. Public responses to the novel 2019 coronavirus (2019-nCoV) in Japan: Mental health consequences and target populations. Psychiatry Clin Neurosci. 2020;74(4):281-2.

9. Bao Y, Sun Y, Meng S, Shi J, Lu L. 2019-nCoV epidemic: address mental health care to empower society. Lancet. 2020;395(10224):e378.

10. Giyer J. The effects of COVID-19 on Health Care professionals. Available from URL:- https://kernvalleysun.com/the-effects-of-covid -19-on-health-care-professionals/. Last accessed 2020 on May 27.

11. Patient escapes from isolation ward in Surat, found dead. Available from URL:- https://www.thehindu.com/news/cities/mumbai/patient-e scapes-from-isolation-ward-in-surat-found-dead/article31478233.ece. Last accessed 2020 on May 27.

12. Kang L, Li Y, Hu S, Chen M, Yang C, Yang BX, et al. The mental health of medical workers in Wuhan, China dealing with the 2019 novel coronavirus. Lancet Psychiatry. 2020;7(3):e14.

13. Bohlken J, Schömig F, Lemke MR, Pumberger M, Riedel-Heller SG. COVID-19-Pandemie: Belastungen des medizinischen Personals [COVID-19 Pandemic: Stress Experience of Healthcare Workers - A Short Current Review. Psychiatr Prax. 2020;47(4):190-7. 
Cite this article: Yadav S, Rawal G. The mental health status of the general public and healthcare professionals in the COVID-19

pandemic. IP Indian J Immunol Respir Med 2020;5(2):72-74. 